\title{
Ontogeny of MAP Kinases in Rat Small Intestine: Premature Stimulation by Insulin of BBM Hydrolases Is Regulated by ERKs but not by p-38 MAP Kinase
}

\author{
SOHEILA MARANDI, NADINE DE KEYSER, CATHERINE STILMANT, ALAIN SALIEZ, \\ ETIENNE MARC SOKAL, YVES GUIOT, AND JEAN-PAUL BUTS \\ Laboratories of Pediatric Gastroenterology and Nutrition [S.M., N.D.K., C.S., E.M.S., J.-P.B.], \\ Experimental Surgery [A.S.], and Pathology [Y.G.], Faculty of Medicine, Université Catholique de \\ Louvain, B-1200 Brussels, Belgium.
}

\begin{abstract}
ABSTRA
Although mitogen-activating protein (MAP) kinases are cru-
cial signal transduction molecules regulating cellular prolifera-
tion, differentiation, and morphology, their ontogenic changes in
the small intestine have not been analyzed. Also, it remains
unknown which pathway of activated MAP kinases regulates the
expression of brush border membrane hydrolases during growth.
Therefore, we have analyzed the mucosal distribution, ontogeny,
and responses to insulin and to inhibitors of p44, p42, and p38
MAP kinases in immature and mature enterocytes using Western
blot analysis and autoradiography after immunoprecipitation,
immunohistochemistry, and in vitro phosphorylation assays. Be-
tween d 10 and 40 postpartum, diphosphorylated active p44/p42
extracellular regulated protein kinases (ERKs) increased in abun-
dance compared with total immunoprecipitated ERKs, and were
highly responsive to exogenous insulin. In concordance, ERK
total activity increased by 4-fold during the same period of
growth and was further enhanced 2-fold by exogenous insulin. In
weaning rats, ERKs were mainly located in membranes of villus
cells and with less intensity in crypt cells. By contrast, p38 MAP
kinase was unresponsive to insulin and was confined to nuclei.
Administration to sucklings of PD 098059, a specific inhibitor of
ERKs, not only inhibited the premature stimulation of sucrase,
lactase, and maltase total activities in response to exogenous
insulin, but also depressed the natural expression of these brush
border membrane enzymes in the absence of insulin stimulation.
\end{abstract}
In concordance, administration of SB 203580, a specific inhibitor of p38 MAP kinase, failed to inhibit both the response of brush border membrane hydrolases to insulin and their natural expression in the absence of insulin stimulation. We conclude that the ontogenic expression of brush border membrane hydrolases and their premature stimulation by insulin are regulated at least in part by the activation of p44/p42 ERKs but not by p38 MAP kinase. (Pediatr Res 52: 180-188, 2002)

\section{Abbreviations}

MAP kinases, mitogen-activating protein kinases

MKK, MAP kinase kinase

BBM, brush border membrane

ERKs, extracellular regulated protein kinases

Shc, Src homology $2 \alpha$-collagen

$\mathrm{SH}_{2}$, Src homology 2

SI, sucrase-isomaltase

PI-3 kinase, phosphatidylinositol-3'-kinase

JNK, c-JUN $N$-terminal protein kinase

SOS, son of sevenless

IR, insulin receptor

IRS-1, insulin receptor substrate 1

IRS-2, insulin receptor substrate 2

Grb2, growth receptor binding protein-2

TCA, trichloroacetic acid
The onset of weaning (d 14-17) in the suckling rat is a critical period during which immature enterocytes exhibit elevated responsiveness to insulin (1). At this time, plasma insulin

Received July 11, 2001; accepted April 2, 2002.

Correspondence and reprint requests: Jean-Paul Buts, M.D., Ph.D., Department of Pediatrics, Cliniques Universitaires Saint-Luc, 10, avenue Hippocrate, B-1200 Brussels, Belgium; e-mail: buts@gype.ucl.ac.be

Supported by grant 629205 from the Fonds Scientifique de la Recherche (FSR), Université Catholique de Louvain, Brussels, Belgium.

DOI: 10.1023/01.PDR.0000020089.88360.67 levels rise markedly (2), whereas milk-borne insulin is still active (3), allowing optimal interaction of the hormone with intestinal IR, which are located on both endoluminal and basolateral membranes of the cell (4). After weaning, the 2 -fold decrease in IR concentration is associated with a reduction in responsiveness of mature enterocytes to the hormone (1, $5)$. Our recent studies $(6,7)$ suggest that the premature induction of SI is triggered by the binding of the hormone to the extracellular $\alpha$-receptor subunit, allowing autophosphorylation of the tyrosine-kinase intrinsic to the juxtamembrane and 
cytoplasmic domains of the $\beta$-receptor subunit. Downstream transduction of the signal into the cell is assumed to occur by the activation of receptor substrates (IRS-1 and -2, and Shc) and tyrosine-phosphorylated proteins associating through $\mathrm{SH}_{2}$ domain $(8,9)$. The final step of the signal leads to the activation of the SI gene promoter with a dose-dependent accumulation of SI mRNA (6), probably by the binding of a nuclear transcription factor [hepatocyte nuclear factor $1,(10,11)$ ] to regulatory elements located upstream of the SI gene promoter $(10,11)$. A recent study (12) has shown that the insulin signal that stimulates BBM hydrolases would be regulated by the cascade of MAP kinases and not by PI-3 kinase or protein kinase B. The MAP kinase cascade activation is mediated by a dualspecificity kinase, termed MKK, which in turn is activated upstream by Raf oncoproteins (9). An interesting feature of MAP kinases is that they require dual phosphorylation on specific threonine and tyrosine residues for their activation. Raf proteins appear to be regulated by both the Ras family of oncoproteins (13) and by the recently described 14-3-3 proteins (14). Cellular activation of Ras is mediated by the guanine nucleotide exchange factor SOS, which, when associated in a complex with the adaptor protein Grb2, binds to the activated IR tyrosine kinase, to IRS-1, and to Shc (9). All these postreceptor signaling molecules have been identified in the rat small intestine $(3,12)$. On stimulation, p44/p42 MAP kinases translocate to the nucleus where they may phosphorylate nuclear transcription factors and thus regulate gene expression (15). Whereas the mechanisms of MAP kinase activation are relatively well understood, the precise physiologic roles of these enzymes remain to be established. Using the intact live animal under conditions relevant to normal insulin responses, the objectives of our study were 1 ) to determine the ontogenic expression of $\mathrm{p} 38, \mathrm{p} 42$, and $\mathrm{p} 44$ MAP kinases in the rat small intestine and 2) to analyze which pathway of MAP kinases is involved in the regulation of the insulin signal.

\section{METHODS}

Reagents. Phenylmethanesulfonic acid, DTT, HEPES sodium salt, SDS (highest purity grade), Triton X-100, leupeptin, pepstatin, aprotinin, EDTA, SB 203580, PD 098059, and myelin basic protein were purchased from Sigma Chemical Co. (Bornem, Belgium). Human recombinant insulin (Actrapid HM) was from Nordisk (Bagsvaerd, Denmark), and ${ }^{125} \mathrm{I}-$ labeled protein A and molecular weight standard (CFA 626) were from Amersham Laboratories (Little Chalfont, U.K.). Polyvinylidene difluoride membranes were obtained from BioRad (Nazareth, Belgium), and protein A-Sepharose 4B was from Amersham Pharmacia Biotechnology (Roosendaal, The Netherlands).

Polyclonal antibodies recognizing $\mathrm{COOH}$ domains of $\mathrm{p} 38$ MAP kinase and ERK-1 and -2 were purchased from Transduction Laboratories (Cambridge, U.K.). To detect with high specificity p38 MAP kinase and p44/p42 ERKs in Western blot analysis, MAb were used. For p38 MAP kinase, an MAb (IgG2 isotype) recognizing the synthetic peptide containing 13 amino acids, HTDDEMTpGYpVATR, corresponding to the diphosphorylated form of p38 MAP kinase with the activation loop, was obtained from Sigma Chemical Co. (St. Louis, MO, U.S.A.). The monoclonal anti-p38 MAP kinase reacts specifically with the active doubly phosphorylated form $\left(\mathrm{Thr}^{180}\right.$-Gly$\mathrm{Tyr}^{182}$ ) on $\mathrm{Thr}^{180}$ and $\mathrm{Tyr}^{182}$ within the regulatory site of the active enzyme. The antibody does not recognize the nonphosphorylated and monophosphorylated forms of p38 MAP kinase, or the nonphosphorylated, monophosphorylated, and diphosphorylated forms of JUN kinase and ERKs. For ERK-1 and -2 , we used an MAb (mouse IgG1 isotype) raised against a synthetic peptide containing 11 amino acids, HTGFLTpEYpVAT, corresponding to the diphosphorylated form of the ERK-activated loop. The antibody is specific for the active diphosphorylated form of ERK-1 and -2 (p44-kD and p42-kD, respectively). The epitope recognized by the antibody contains the phosphorylated threonine and tyrosine residues within the regulatory site of active ERK-1 and -2 (Thr ${ }^{183}$ and $\mathrm{Tyr}^{185}$ in ERK-2).

The antibody does not recognize the nonphosphorylated or the monophosphorylated forms of ERK-1 and -2 or the diphosphorylated forms of JUN kinase and p38 MAP kinase.

Animals. All procedures were approved by the University Ethical Committee for Animal Welfare (Fonds de la Recherche Scientifique Médicale, Université Catholique de Louvain, Brussels, Belgium). Litters of Wistar rats, acclimatized to standard conditions of room temperature, light-dark cycles, and feeding schedules, were used. To equalize nursing and feeding conditions, litters were reduced to six pups per lactating mother. During the nursing period, pups remained with the mothers in polystyrene cages and had free access to milk. They were weaned progressively onto a pelleted diet (AO3, UAR, Villemoisson-sur-Orge, France) beginning on d 15 postpartum. To identify the phosphorylated forms of MAP kinases and ERK-1 and -2, animals were injected under ether anesthesia after $2-3 \mathrm{~h}$ of fasting. The femoral vein was exposed after a small incision, and saline solution $(0.9 \%)$ with $\left(10^{-6} \mathrm{M}\right)$ or without insulin was slowly injected $(1 \mathrm{~mL} / \mathrm{min})$.

After infusion ( 3 to $5 \mathrm{~min}$ ), the animal was killed and the small intestine was excised rapidly, trimmed of fat and mesentery, and rinsed with ice-cold saline solution. After being opened longitudinally, the mucosa was scraped on ice between glass slides, weighed, and used for protein extraction or stored at $-170^{\circ} \mathrm{C}$ in liquid nitrogen. To study ontogenic changes in p38 MAP kinase and p44/p42 ERK-1 and -2, animals were treated with insulin or with an equivalent amount of saline solution and killed at d 10,20,30, and 40 postpartum.

Treatment and schedules. To inhibit ERK-1 and -2, PD 098059, a specific inhibitor of MKK that phosphorylates specifically ERK-1 and -2, was injected i.p. to sucklings and weanling rats at the dose of $2 \mu \mathrm{g} / \mathrm{g}$ body weight twice daily from d 12 to d 14 postpartum and from d 16 to $\mathrm{d} 18$ postpartum. Control groups received insulin $(5 \mathrm{mU} \cdot \mathrm{g}$ body weight ${ }^{-1} \cdot \mathrm{d}^{-1}$ in $100 \mu \mathrm{L}$ ) or saline solution according to the same schedule. To confirm the inhibitory effect of PD 098059 on ERKs activities in vivo an additional experiment was conducted in 22-d-old rats. Weanling rats (d 20) were treated i.p. with PD 098059 ( $2 \mu \mathrm{g} / \mathrm{g}$ body wt twice daily) from $\mathrm{d} 20$ to $\mathrm{d}$ 22. At d 22, the specific and total activities of ERKs and of sucrase were measured as described in the section "Enzyme 
Assays." Control rats received the vehicle according to the same schedule. To determine whether p38 MAP kinase could be involved in the signal pathway by which insulin enhances BBM hydrolases, SB 203580, a specific inhibitor of p38 MAP kinase, was injected i.p. to sucklings and weanling rats at the dose of $0.5 \mu \mathrm{g} / \mathrm{g}$ body weight twice daily. Control groups received insulin $\left(5 \mathrm{mU} \cdot \mathrm{g}\right.$ body weight $\left.{ }^{-1} \cdot \mathrm{d}^{-1}\right)$ or saline solution following the same schedule. In some experiments the inhibitors were injected $1 \mathrm{~h}$ before the injection of insulin.

Extraction of phosphotyrosine proteins. The method of Rothenberg et al. (16) was used with slight adaptations (12). Briefly, samples of intestinal mucosa were homogenized for 1 min in a solubilization buffer $(1: 5 \mathrm{vol} / \mathrm{vol})$ maintained at $100^{\circ} \mathrm{C}$ in a water bath ( $2 \mathrm{~min}$ ) with an Ultraturax generator (Janke and Kunkel, Staugen, Germany) operated at maximum speed. The solubilization buffer was composed of $2 \%$ SDS, $100 \mathrm{mM}$ HEPES (pH 7.8 at $22^{\circ} \mathrm{C}$ ), $10 \mathrm{mM}$ EDTA, $100 \mathrm{mM} \mathrm{NaCl}$, and $50 \mathrm{mM}$ DTT. The homogenate was heated further to boiling with stirring for $2 \mathrm{~min}$ and left to cool to $22^{\circ} \mathrm{C}$.

After centrifugation for $2 \mathrm{~h}$ at $18^{\circ} \mathrm{C}$ in a Beckman (Analys Namur Belgium) type 35 rotor ultracentrifuge $(149,000 \times g)$, the supernatant was acidified with $100 \%$ TCA, added slowly dropwise at $22^{\circ} \mathrm{C}$ to a final concentration of $10 \%$. The mixture was then cooled at $4^{\circ} \mathrm{C}$ overnight. The precipitate was collected by centrifugation in a Sorvall RC-5B centrifuge (Analys) at $4^{\circ} \mathrm{C}$ for $10 \mathrm{~min}$.

The precipitate was washed once with 25 vol of $10 \%$ TCA at $4{ }^{\circ} \mathrm{C}$, and the TCA was extracted by six washes, each with 25 vol of ethanol and diethyl ether $(1: 1 \mathrm{vol} / \mathrm{vol})$ at $4^{\circ} \mathrm{C}$. The precipitate was dried under vacuum (Speed Vac, Savant Thermalife, Brussels, Belgium) and pulverized to a fine powder. In this form, the extracted proteins can be stored for at least $1 \mathrm{y}$ at $-170^{\circ} \mathrm{C}$ without apparent degradation or significant loss of phosphorylated protein content.

Immunoprecipitation of ERK-1 and -2 and p38 MAP kinase. For immunoprecipitation, $0.05 \mathrm{~g}$ of dry tissue powder ( $\pm 15 \mathrm{mg}$ of proteins) was dissolved in $1 \mathrm{~mL}$ of $0.1 \mathrm{~N} \mathrm{NaOH}$ with vigorous stirring at $22^{\circ} \mathrm{C}$ for $5 \mathrm{~min}$. The resulting solution was then neutralized rapidly to $\mathrm{pH} 8$ with 2 vol of $100 \mathrm{mM}$ Tris- $\mathrm{HCl}$ and $1 \mathrm{mM}$ EDTA with a cocktail of protease inhibitors including $0.2 \mathrm{mM}$ phenylmethanesulfonic acid, $1 \mu \mathrm{g} / \mathrm{mL}$ leupeptin, and $1 \mu \mathrm{g} / \mathrm{mL}$ aprotinin. Polyclonal antibodies recognizing the $\mathrm{COOH}$ terminal sequences of $\mathrm{p} 38 \mathrm{MAP}$ kinase or of ERK-1 and -2 were coated on protein A-Sepharose 4B beads $(2-4 \mu \mathrm{g} \mathrm{IgG} / \mathrm{mL})$ by incubating the antibodies in $75 \mu \mathrm{L}$ of a $50 \%$ bead slurry $/ \mathrm{mL}$ of immunoprecipitation buffer at $4^{\circ} \mathrm{C}$ for $12 \mathrm{~h}$ with gentle agitation. MAP kinases were then complexed with the antibodies by incubating the coated beads with the extracted proteins in immunoprecipitation buffer at $4^{\circ} \mathrm{C}$ for $4 \mathrm{~h}$. Immune complexes were washed twice by resuspension and brief centrifugation in $1 \mathrm{~mL}$ of wash buffer containing $1 \%$ Triton $\mathrm{X}-100,0.1 \% \mathrm{SDS}, 100 \mathrm{mM} \mathrm{NaCl}$, and $50 \mathrm{mM}$ Tris, $\mathrm{pH}$ 7.3 at $22^{\circ} \mathrm{C}$, and twice more in the same buffer lacking $\mathrm{NaCl}$. After aspirating the excess wash buffer, the immunoprecipitated proteins were solubilized in $30-50 \mu \mathrm{L}$ of Laemmli's buffer (17) and boiled at $100^{\circ} \mathrm{C}$ for 5 min before being layered onto gel slots.
Electrophoresis and immunoblotting. Immunoprecipitated proteins were separated by SDS-PAGE in $10 \%$ polyacrylamide gels as described previously $(4,12)$. Electrotransfer of proteins to polyvinylidene difluoride membranes was performed for 90 min at $50 \mathrm{~V}$ as described by Towbin et al. (18). Nonspecific protein binding was reduced by preincubating the membranes overnight at $4{ }^{\circ} \mathrm{C}$ in blocking buffer containing 5\% BSA and $1 \%$ ovalbumin in TN buffer $(10 \mathrm{mM}$ Tris $\mathrm{pH} 7.2$ and $0.9 \%$ $\mathrm{NaCl})$. The membrane was then incubated with antibodies recognizing either the total amount or the active diphosphorylated form (Thr ${ }^{180}$-p-Gly Tyr ${ }^{182}$-p) of p38 MAP kinase and the total amount or the active diphosphorylated form $\left(\mathrm{Thr}^{183}\right.$-pGlu $\mathrm{Tyr}^{185}-\mathrm{p}$ ) of ERK-1 and -2 at a dilution of $1 / 200$ to $1 / 10,000$ in blocking buffer for $2 \mathrm{~h}$ at $22^{\circ} \mathrm{C}$. Thereafter, the membrane was washed twice for $10 \mathrm{~min}$ each in TNT buffer (TN buffer with $0.1 \%$ Tween), twice for $10 \mathrm{~min}$ each in TN buffer containing $0.05 \%$ Nonidet P-40, and twice for $10 \mathrm{~min}$ in TNT buffer. The blots were then incubated with $50 \mu \mathrm{Ci}$ of ${ }^{125}$ I-labeled protein A (Amersham) in $10 \mathrm{~mL}$ of blocking buffer for $1 \mathrm{~h}$ at $22^{\circ} \mathrm{C}$ and washed again as described above. Bound proteins were detected by autoradiography using $24 \times 30 \mathrm{~cm}$ Fuji films (St-Nicolas, Belgium) at $-70^{\circ} \mathrm{C}$ for $24-72 \mathrm{~h}$ as described previously $(4,12)$. Equivalent amounts of proteins determined by the method of Lowry et al. (19) were immunoprecipitated, and equal amounts of immunoprecipitated material were layered onto gel slots. Band intensity was expressed in arbitrary OD units whereas relative abundance was expressed in arbitrary volume units $\left(\mathrm{OD} \times \mathrm{mm}^{2}\right)$.

Enzyme assays. To measure the intestinal activity of ERK-1 and -2 , mucosal homogenates were prepared $(1: 3 \mathrm{vol} / \mathrm{vol})$ in a buffer containing HEPES $50 \mathrm{mM}$, EDTA $1 \mathrm{mM}$, EGTA $1 \mathrm{mM}$, $\mathrm{Na}_{3} \mathrm{VO}_{4} 0.5 \mathrm{mM}, \mathrm{NaF} 20 \mathrm{mM}, \mathrm{Na}_{4} \mathrm{PO}_{7} 5 \mathrm{mM}$, and $\beta$-mercaptoethanol $0.1 \%$ with antiproteases $(\mathrm{pH} 7.5)$ from insulin-treated rats $(\mathrm{d} 10,20,30$ postpartum) and controls $(\mathrm{d} 10,20,30,40$ postpartum) under nondenaturing conditions. Enzymes were immunoprecipitated with the corresponding specific antibodies bound to protein A-Sepharose 4B beads in the same buffer containing a cocktail of antiproteases. ERK-1 and -2 activities were determined by the phosphorylation of the myelin basic protein (phosphorylated on serine and threonine residues) used as substrate in the presence of $\left[\gamma_{-}{ }^{32} \mathrm{P}\right] \mathrm{ATP}-\mathrm{Mg}$ (sp act $>5000$ $\mathrm{Ci} / \mathrm{mM}$, Amersham). Blanks were handled exactly like samples, except that the immunoprecipitated enzyme was omitted from the reaction. The activities were linear for up to $20 \mathrm{~min}$ of incubation time $\left(30^{\circ} \mathrm{C}\right)$ and were proportional to the amount of enzyme used in the reaction. ERK-1 and -2 activity was expressed as total activity (picomoles of substrate phosphorylated per minute per gram total intestinal mucosa) because the diphosphorylated forms of ERK-1 and -2 that were detected by Western blot at different ages were extracted from the whole intestinal mucosa. BBM were purified according to the method of Schmitz et al. (20) using calcium chloride for membrane precipitation. Sucrase, lactase, and maltase activities were assayed in intestinal mucosa or BBM samples by standard methods (21). Total enzyme activities were expressed as micromoles of substrate hydrolyzed per minute per milligram of total BBM purified from the whole intestinal mucosa or per total intestinal mucosa. 
Immunohistochemistry. Samples of duodenum and small intestine were fixed by immersion in buffered formaldehyde at $4 \%$ for $24 \mathrm{~h}$ and embedded in paraffin. Five-micrometer sections were dried for $16 \mathrm{~h}$ at $37^{\circ} \mathrm{C}$. After paraffin removal, rehydration, and peroxidase inhibition, sections were successively incubated for 30 min with a normal goat serum (1/10; ICN Biomedicals, Cleveland, OH, U.S.A.) and overnight with either an anti-p38 polyclonal antibody (C-20, SC-535; Santa Cruz Biotechnology, Santa Cruz, CA, U.S.A.) or an antiERK-2 polyclonal antibody (C-14, SC-154; Santa Cruz Biotechnology) diluted $1 / 200$ in Tris-buffered saline (TBS, $\mathrm{pH}$ 7.4). After several washes with TBS buffer, the specific rabbit antibodies were detected by a biotinylated anti-rabbit antibody (1/500; Chemicon, Temecula, CA, U.S.A.), then with streptavidin-peroxidase conjugate (dilution: 1/1000; Boehringer Mannheim, Mannheim,Germany). Finally, the peroxidase activity was revealed for $10 \mathrm{~min}$ by immersion in a solution of DAB chromogen (3,3'-diaminobenzidine hydrochloride $0.05 \%$ wt/vol in TBS; Amersham, Cardiff, U.K.) supplemented with $0.02 \%$ hydrogen peroxide. After several washes, the slides were counterstained in Mayer's hematoxylin, dehydrated, and covered with a coverslip. Negative controls were obtained with the incubation of a TBS-normal goat serum $1 \%$ solution in place of the first polyclonal antibody (22).

Calculations and statistics. All data are given as mean \pm $\mathrm{SD}$. If not indicated, SD represents $<10 \%$ of the mean. Differences between control and insulin-treated animals were tested for statistical significance $(p<0.05)$ using the nonparametric Mann-Whitney $U$ test.

\section{RESULTS}

Ontogenic changes. Because phosphorylated kinases are susceptible to rapid phosphatase-mediated dephosphorylation and proteolysis both in vivo (23) and during extraction procedures (24), we rapidly homogenized the intestinal mucosa from insulin-treated rats and control animals at $100^{\circ} \mathrm{C}$ in a buffer containing $2 \%$ SDS and $50 \mathrm{mM}$ DTT. The final precipitate yielded from the whole mucosa of 40-d-old rats $0.1 \pm 0.06 \mathrm{~g}$ powder $/ \mathrm{g}$ wet intestinal mucosa $(n=30)$ and $0.57 \pm 0.09 \mathrm{~g}$ protein/g dry powder. For suckling rats, two mucosal scrapings from the total intestinal length (including the duodenum) were pooled and considered as one sample. We found no difference between the amount of proteins extracted from the intestinal mucosa of insulin-treated rats and control animals. Immunoprecipitations of p38 MAP kinase with an anti-p38 polyclonal antibody followed by detection in immunoblot of the diphosphorylated form of the enzyme (Thr-p-Gly-Tyr-p) revealed a signal that was present in both insulin-treated rats and control animals (at d 20, 30, and 40 postpartum; Fig. 1). For d 10, no signal was detected.

Figure 2 presents the total expression of $\mathrm{p} 38$ MAP kinase at different ages. Therefore, immunoprecipitation of p38 MAP kinase with an anti-p38 polyclonal antibody was followed by the detection in immunoblot of the total immunoprecipitated p38 protein using the same polyclonal antibody. Figure 2 reveals a major signal of p38 ( $\alpha$-isoform) and a weak signal corresponding to the $\beta$-isoform. The signal of $\alpha$-p38 was

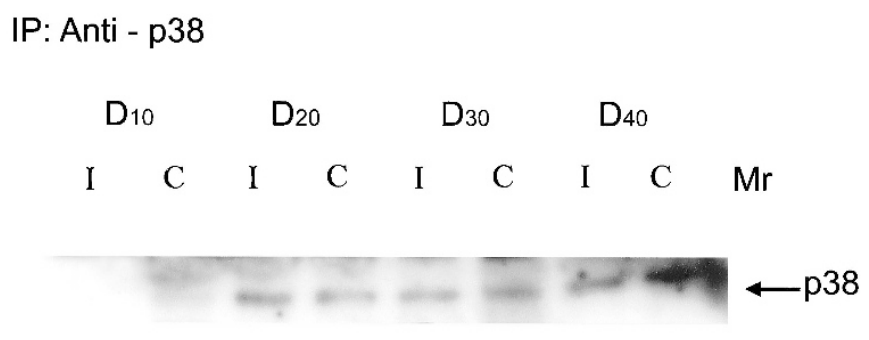

Wb: Anti Thr - p - Gly - Tyr - p

Figure 1. Immunoprecipitation of $\mathrm{p} 38 \mathrm{MAP}$ kinase from the whole intestinal mucosa of rats at different ages (d 10, d 20, d 30, d 40 postpartum) treated with insulin $(I)$ or with saline $(C)$. After transfer, the diphosphorylated active form (Thr-p-Gly-Tyr-p) of the enzyme was detected by Western blot using a specific $\mathrm{MAb}$. Note the presence of a single band at $-38 \mathrm{kD}$ ( $M R$, relative mobility) in both control and insulin-treated rats.

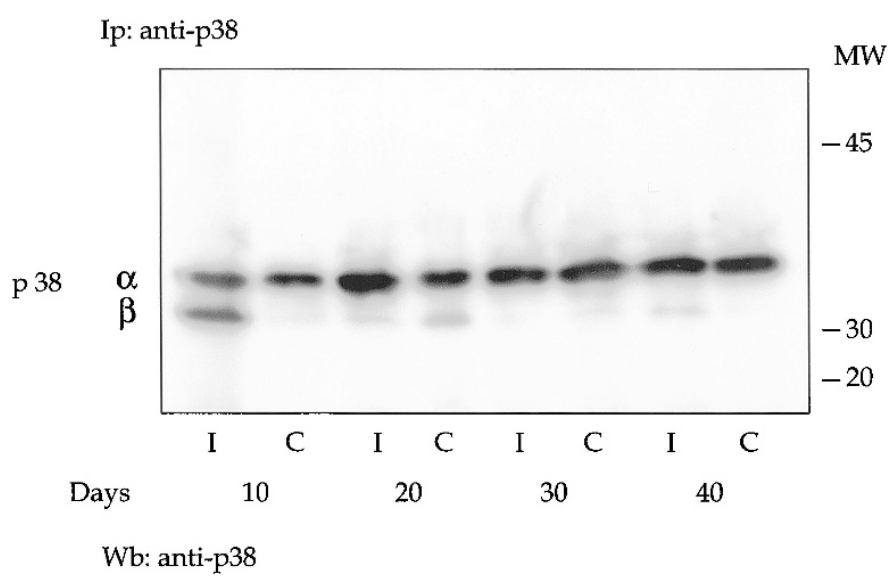

Figure 2. Immunoprecipitation of p38 MAP kinase from the whole small intestinal mucosa of rats at different ages (d 10, d 20, d 30, d 40) treated with insulin $(I)$ or with saline $(C)$. After transfer, immunoprecipitated p38 was detected by Western blot using the same polyclonal anti-p38 antibody recognizing both active and nonactive enzyme. Note the presence of a major signal at $-38 \mathrm{kD}$ ( $\alpha$-isoform) and a weak signal corresponding to the $\mathrm{p} 38 \beta$-isoform.

present in both insulin-treated rats and control animals, whatever the age of the animals. Optical densitometric measurements of the relative abundance of the signals (derived from two separate experiments) indicated that the expression of $\mathrm{p} 38$ protein remained unchanged during growth, whereas the diphosphorylated p38 MAP kinase increased from $\mathrm{d} 10$ to $\mathrm{d} 40$ (Table 1). The ratio of diphosphorylated to total immunoprecipitated p38 MAP kinase increased with age from 0 to 0.9 . However, there was no difference between insulin-treated rats and control animals for both total immunoprecipitated and diphosphorylated p38 MAP kinase. This demonstrates that phosphorylation and activation of p38 MAP kinase is not regulated by insulin.

The detection in immunoblots of the diphosphorylated forms of ERK-1 and -2 with a specific MAb recognizing the sequence Thr-p-Glu-Tyr-p revealed two bands at $44 \mathrm{kD}$ and $42 \mathrm{kD}$, respectively (Fig. 3). In sucklings (d 10) no signal of the diphosphorylated enzymes could be detected, whereas in 
Table 1. Optical densitometric measurements of total immunoprecipitated and diphosphorylated p38 MAP kinase in insulin-treated rats (I) and control animals $(C)^{*}$

\begin{tabular}{|c|c|c|c|c|c|c|c|c|}
\hline & \multicolumn{2}{|c|}{ d 10} & \multicolumn{2}{|c|}{ d 20} & \multicolumn{2}{|c|}{ d 30} & \multicolumn{2}{|c|}{$\mathrm{d} 40$} \\
\hline & $\mathrm{I}$ & $\mathrm{C}$ & I & $\mathrm{C}$ & I & $\mathrm{C}$ & I & $\mathrm{C}$ \\
\hline Total immunoprecipitated p38 MAP kinase & $8.2 \pm 0.1$ & $9.04 \pm 0.2$ & $10.2 \pm 0.3$ & $9.2 \pm 0.2$ & $10.3 \pm 0.1$ & $9.8 \pm 0.1$ & $10.6 \pm 0.2$ & $10.1 \pm 0.2$ \\
\hline Diphosphorylated p38 MAP kinase & $\mathrm{NS} \dagger$ & NS & $4.0 \pm 0.1$ & $3.7 \pm 0.10$ & $4.5 \pm 0.8$ & $5.4 \pm 0.7$ & $7.6 \pm 0.1$ & $9.8 \pm 0.1$ \\
\hline $\begin{array}{l}\text { Ratio diphosphorylated/total immunoprecipitated } \\
\text { p38 MAP kinase }\end{array}$ & & - & 0.39 & 0.40 & 0.43 & 0.55 & 0.71 & 0.97 \\
\hline
\end{tabular}

* Units are mean $\pm \mathrm{SD}$, units are expressed as arbitrary units of abundance of the signal (OD units $\left.\times \mathrm{mm}^{2}\right)$.

$\uparrow \mathrm{NS}$, no signal detected.

IP: Anti-ERK 1,2

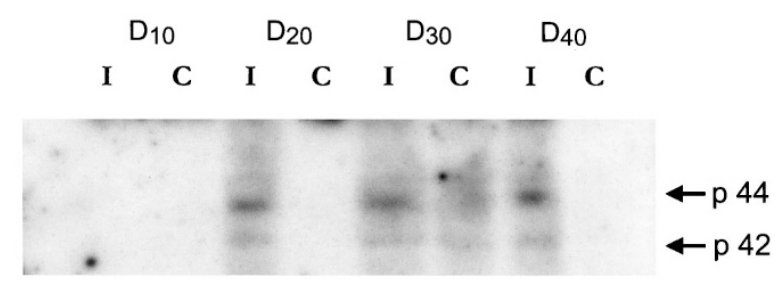

Wb: Thr - p - Glu - Tyr - p

Figure 3. Immunoprecipitation of ERKs from the whole intestinal mucosa of rats at different ages treated with insulin $(I)$ or saline $(C)$. After transfer the diphosphorylated forms of the enzymes (Thr-p-Glu-Tyr-p) were detected by Western blot, using a specific MAb recognizing the diphosphorylated sequence. Note the presence of two separate signals at -44 and $-42 \mathrm{kD}$. These signals were clearly detected in insulin-treated rats (d 20, d 30, d 40) and were weak (d 30) or virtually absent in control rats (d 10).

weanling (d 20) and weaned rats (d 30, d 40), the two signals were clearly detected in insulin-treated rats but were weak or virtually absent in control rats.

Figure 4 shows the total expression of p44/p42 ERKs at different ages in insulin-treated rats and control animals. ERKs were detected in immunoblot with a polyclonal antibody recognizing nonphosphorylated, monophosphorylated, and diphosphorylated forms of p44/p42. ERKs were detected as an intense double signal present in both insulin-treated rats and

IP: Anti-ERK 1,2

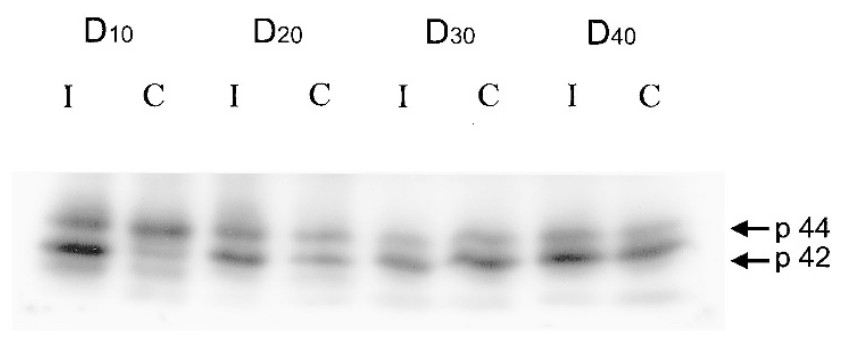

\section{Wb:Anti-ERK 1,2}

Figure 4. Immunoprecipitation of ERKs from the whole small intestinal mucosa of rats at different ages (d 10, d 20, d 30, d 40) treated with insulin (I) or with saline $(C)$. After transfer, immunoprecipitated ERKs were detected by Western blot using the same polyclonal anti-ERKs antibody recognizing both active and nonactive enzymes. Note the presence of a major doublet at $-44 \mathrm{kD}$ and $-42 \mathrm{kD}$, respectively. The weak signal below the doublet corresponds to the light chain of the antibody. control animals, whatever the age of the animals. Optical densitometric measurements of total immunoprecipitated and diphosphorylated forms of p44/p42 expressed as arbitrary units of abundance of the signals are detailed in Table 2. Total immunoprecipitated p44 or p42 ERKs did not significantly change during growth in insulin-treated rats and control animals. However, the ratio of total immunoprecipitated to diphosphorylated p44 ERK-1 increased from 0 to 0.84 between d 10 and d 40 postpartum. Likewise, the same ratio for p42 ERK-2 increased from 0 to 0.37 between d 10 and d 40 . Thus, active diphosphorylated p44/p42 ERKs appear to increase with age, although the total expression of $\mathrm{p} 44 / \mathrm{p} 42$ proteins remains constant. The responsiveness of ERKs to insulin and the increasing expression of active p44/p42 ERKs in the small intestine during age were further confirmed by measuring changes in the total activity of the enzymes. As detailed in Table 3, the total enzyme activity expressed as picomoles per minute and per total intestinal mucosa (including the duodenum) increased by 4-fold in control rats between d 10 and d 40 and was enhanced in each age group by 2 -fold in response to insulin.

Immunohistochemistry revealed that the specific staining for ERK-1 and -2 (phosphorylated and nonphosphorylated) was mostly confined to the apical and basolateral membranes of villus cells (Fig. 5A) and to a lesser extent in crypt cells. Staining for p38 MAP kinase (phosphorylated and nonphosphorylated) was more abundant than for ERKs, with a maximal concentration in the duodenum (Fig. 5B). By contrast with ERKs, p38 MAP kinase was detected almost exclusively in the nuclei of enterocytes.

Response of rat immature intestinal mucosa and $B B M$ hydrolases to in vivo administration of inhibitors. ERK-1 and -2 are known to be critical enzymes regulating the mitogenic effects of insulin, cell proliferation, and differentiation. Therefore, PD 098059, a specific inhibitor of MAP kinase, was administered i.p. to sucklings (d 12 to $\mathrm{d} 14$ ) at low doses (2 $\mu \mathrm{g} / \mathrm{g}$ body wt twice daily; median lethal dose, $200 \mu \mathrm{g} / \mathrm{g}$ ) for $48 \mathrm{~h}$, either alone or $1 \mathrm{~h}$ before the administration of insulin ( 5 $\mathrm{mU} / \mathrm{g}$ body wt). The results are detailed in Table 4. Compared with saline-treated control animals, sucklings treated with PD 098059 had similar weight gain and intestinal length but lower mucosal mass expressed in milligrams per centimeter of gut length. The total BBM activities of sucrase, lactase, and maltase (per total intestine) were significantly decreased in the PD 098059-treated group compared with saline-treated control animals. BBM protein concentration was also significantly decreased in the PD 098059-treated group. 
Table 2. Optical densitometric measurements of total immunoprecipitated and diphosphorylated forms of p44/p42 ERKs in insulin-treated rats (I) and control animals (C)*

\begin{tabular}{|c|c|c|c|c|c|c|c|c|}
\hline & \multicolumn{2}{|c|}{ d 10} & \multicolumn{2}{|c|}{ d 20} & \multicolumn{2}{|c|}{ d 30} & \multicolumn{2}{|c|}{ d 40} \\
\hline & I & $\mathrm{C}$ & I & $\mathrm{C}$ & I & $\mathrm{C}$ & I & $\mathrm{C}$ \\
\hline Total immunoprecipitated p44 ERK1 & $5.7 \pm 0.1$ & $4.18 \pm 0.1$ & $5.9 \pm 0.1$ & $3.7 \pm 0.1$ & $5.7 \pm 0.1$ & $2.9 \pm 0.13$ & $4.6 \pm 0.1$ & $4.0 \pm 0.1$ \\
\hline Ratio & - & - & 0.50 & - & 0.61 & 0.41 & 0.84 & - \\
\hline Total immunoprecipitated P42 ERK2 & $6.7 \pm 0.08$ & $3.0 \pm 0.05$ & $4.6 \pm 0.07$ & $2.6 \pm 0.08$ & $5.0 \pm 0.07$ & $5.5 \pm 0.07$ & $4.3 \pm 0.06$ & $4.3 \pm 0.05$ \\
\hline Diphosphorylated P42 ERK2 & NS & NS & $1.06 \pm 0.02$ & NS & $1.64 \pm 0.02$ & $1.0 \pm 0.01$ & $1.57 \pm 0.03$ & NS \\
\hline Ratio & - & - & 0.24 & - & 0.32 & 0.18 & 0.37 & - \\
\hline
\end{tabular}

* Units are mean $\pm \mathrm{SD}$; units are expressed as arbitrary units of abundance of the signal (OD units $\times \mathrm{mm}^{2}$ ).

$\dagger$ NS, no signal detected.

Table 3. Ontogenic changes in total activity of ERKs in rat small intestine and response to insulin before (d 10) and after weaning (d 30)

\begin{tabular}{|c|c|c|c|c|}
\hline & d 10 & d 20 & d 30 & d 40 \\
\hline No. of animals & 5 & 6 & 8 & 7 \\
\hline Total mucosal weight (g) & $0.36 \pm 0.04$ & $1.31 \pm 0.23$ & $2.60 \pm 0.07$ & $2.85 \pm 0.11$ \\
\hline \multicolumn{5}{|l|}{ ERK total intestinal activity* } \\
\hline Insulin-treated rats & $4.85 \pm 0.20$ & $9.80 \pm 1.20$ & $14.54 \pm 3.03$ & $17.62 \pm 3.71$ \\
\hline Fold increase $v s$ controls & 2.06 & 2.1 & 2.1 & 2.17 \\
\hline
\end{tabular}

* Total activity is expressed in picomoles per minute per gram of total intestinal mucosa.

The same experiment was repeated in weanling rats treated from d 16 to $d 19$ postpartum. At d 19 postpartum, total activity of sucrase was decreased in the PD 098059-treated group compared with the saline-treated control animals $(150 \pm 15.7$ versus $197.1 \pm 23.0 \mathrm{mU}$ per total $\mathrm{BBM}, p<0.05)$. Likewise, lactase total activity was also depressed by the ERKs inhibitor compared with control animals (171 \pm 28 versus $366 \pm 31 \mathrm{mU}$ per total BBM, $p<0.01$ ).

Table 4 also compares the effects of the ERK inhibitor in insulin-treated rats (d 12 to $\mathrm{d} 14$ ). There was no difference between insulin-treated control animals and experimental rats receiving both PD 098059 and insulin regarding body weight gain and intestinal length.

Mucosal mass expressed per centimeter of gut length was significantly decreased in the group receiving PD 098059 and insulin. Total BBM activities of sucrase, lactase, and maltase were significantly decreased in the PD $098059+$ insulintreated group, by 1.61-fold, 1.80-fold, and 1.40-fold, respectively, compared with the insulin-treated control group. These data demonstrate that the administration of PD 098059, an irreversible inhibitor of ERKs, inhibited partially the premature stimulation of BBM hydrolases by insulin and inhibited in nonstimulated sucklings as well as in weanling rats the natural expression of these enzymes. To confirm the inhibitory effect of PD 098059 in vivo on ERK activity, the enzyme inhibitor was administered i.p. $(2 \mu \mathrm{g} / \mathrm{g}$ body wt twice daily) from $\mathrm{d} 20$ to $\mathrm{d} 22$ postpartum. Results are detailed in Table 5. Both the specific and total activities of sucrase and of ERKs were decreased by 2.9- to 3.7-fold in the PD 098059-treated group compared with the control group receiving the vehicle.

By contrast, as shown in Table 6, the administration of SB 203580, a specific inhibitor of p38 MAP kinase, when given to untreated suckling rats failed to depress mucosal mass, gut length, and the total activities of sucrase, lactase, or maltase compared with the values measured in the control group. Surprisingly, in rats treated with insulin, SB 203580 enhanced the premature induction of sucrase by 2.7 -fold and the stimulation of maltase by 1.68 -fold but did not affect lactase total activity.

\section{DISCUSSION}

The MAP kinase cascades are one of the most intensely studied groups of signal transduction molecules. These signaling pathways are present in all eukaryotes and have been implicated in many physiologic processes including cell growth, differentiation, oncogenic transformation, immune responses, and apoptosis (25). MAP kinase cascades are organized by a core signaling module consisting of three levels of protein kinases: MAP kinase kinase kinase, MKK, and MAP kinase. The superfamily of MAP kinase includes the ERK-1 and -2 (also termed p44/p42 MAP kinase), JNK (also termed stress-activated protein kinase or SAPK1), and p38 MAP kinase (also termed SAPK2).

These are the terminal enzymes of three- to four-kinase cascades in which each kinase phosphorylates and thereby activates the next member of the sequence. The activated MAP kinase phosphorylates other protein kinases and transcription factors to achieve the desired response to extracellular stimulation. ERKs generally transmit signals of extracellular origin to the nucleus, leading to cell proliferation and differentiation, whereas p 38 MAP kinase and JNK are both mostly responsive to stress, cytokines, and changes in extracellular osmolarity (26) and have been implicated in cell death and apoptosis in several cellular systems (27).

Up to now, the ontogenic changes in ERKs of the rat intestinal tract have not been studied. Also, it remains unknown whether ERKs and p38 MAP kinase could regulate the ontogenic expression of BBM enzymes at weaning and transmit the signal of insulin, which enhances prematurely these intestinal enzymes. We have studied the role of p38 MAP kinase because changes in cell hydration induced by insulin are dependent on PI-3 kinase, which leads to the activation of p38 MAP kinase 

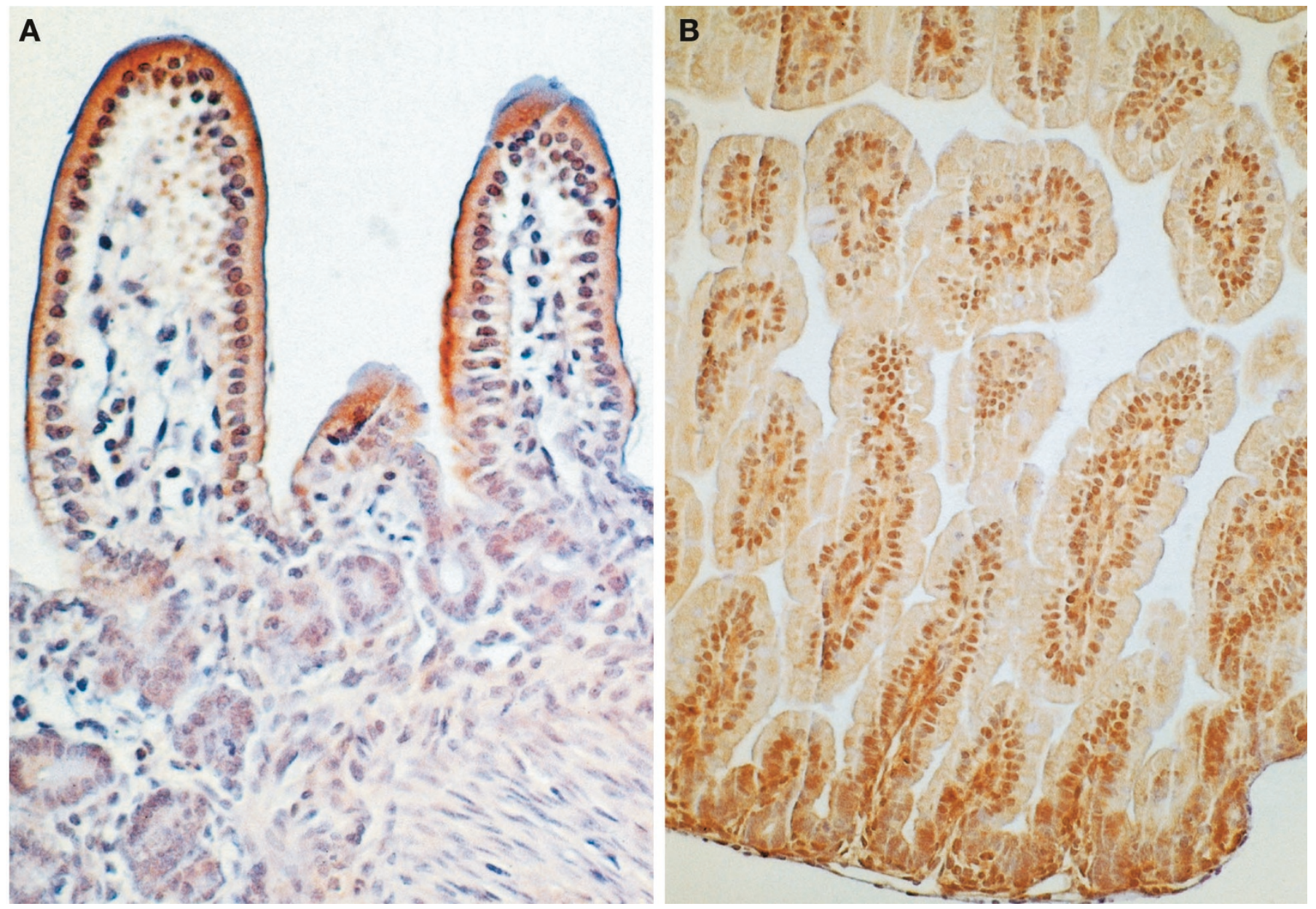

Figure 5. $A$, staining of ERK-2 in the duodenojejunum of insulin-treated weanling rats (see "Methods"). ERK-2 was located in membranes of enterocytes covering the whole villus and with less intensity in crypt cells (magnification, $\times 2300$ ). $B$, staining of $\mathrm{p} 38$ MAP kinase in the duodenojejunum of insulin-treated weanling rats. Abundant staining for p38 was detected in the nuclei of enterocytes (magnification, $\times 2100$ ). Control sections using nonspecific antibody instead of the anti-ERK or anti-p38 antibody showed no staining at all. In addition, intensity of staining decreased proportionally with the dilution of the specific antibody.

Table 4. Response of rat immature small intestine to p44, p42 ERKs inhibitor PD 098059 (d 12 to d 14 postpartum)*

\begin{tabular}{|c|c|c|c|c|c|c|}
\hline Variable & Saline controls & PD 098059 & $\begin{array}{c}P \\
\text { value } \dagger\end{array}$ & Insulin & $\begin{array}{l}\text { PD } 098059 \\
+ \text { Insulin }\end{array}$ & $\begin{array}{c}P \\
\text { value† }\end{array}$ \\
\hline No. of rats & 8 & 8 & & 8 & 8 & \\
\hline \multicolumn{7}{|l|}{ Body wt (g) } \\
\hline Final (d 14) & $23.0 \pm 1.80$ & $24.2 \pm 0.85$ & NS & $25.5 \pm 1.87$ & $25.3 \pm 1.22$ & NS \\
\hline Intestinal length $(\mathrm{cm})$ & $44.4 \pm 2.46$ & $43.4 \pm 2.03$ & NS & $49.9 \pm 1.18$ & $49.3 \pm 1.93$ & NS \\
\hline Mucosal wt (mg/cm) & $9.90 \pm 2.46$ & $7.04 \pm 1.16$ & $<0.05$ & $10.4 \pm 1.49$ & $8.17 \pm 1.06$ & $<0.01$ \\
\hline Maltase total activity & $698 \pm 137$ & $451 \pm 68$ & $<0.05$ & $2154 \pm 325$ & $1534 \pm 301$ & $<0.05$ \\
\hline BBM protein $(\mathrm{mg} / \mathrm{mL})$ & $4.50 \pm 1.02$ & $3.10 \pm 0.74$ & $<0.05$ & $6.68 \pm 1.40$ & $4.67 \pm 0.96$ & $<0.05$ \\
\hline
\end{tabular}

* Data are expressed as mean $\pm \mathrm{SD}$.

$\dagger$ Probability vs saline controls; NS, not significant.

$\ddagger$ Probability $v$ insulin controls.

$\S$ Total activity represents $\mathrm{mU}$ per total intestinal BBM.

II NA, no activity detected.

(28). Our data demonstrate that the activity of p44 and p42 ERKs increases by 4 -fold in the small intestine between $\mathrm{d} 10$ and $\mathrm{d} 40$ with a marked rise during weaning (d 20) in concordance with the upsurge in cell proliferation and differentiation (29) that occurs at the same age. Likewise, the detection by autoradiography of the diphosphorylated active forms of p44 and p42 ERKs revealed a high degree of responsiveness to insulin and an increase in the abundance of the signals during growth, although the total immunoprecipitated forms of ERKs (active and nonactive proteins) changed very little. ERKs were 
Table 5. Effects of PD 098059 administered in vivo in weanling rats (d 20) on sucrase activity and ERK activity*

\begin{tabular}{|c|c|c|c|}
\hline Variable & $\begin{array}{l}\text { Controls } \\
\text { (vehicle) }\end{array}$ & $\begin{array}{c}\text { PD } 098059 \\
(2 \mu \mathrm{g} \cdot \mathrm{g} \cdot \text { body } \\
\left.\mathrm{wt}^{-1} \cdot \mathrm{d}^{-1}\right)\end{array}$ & $\Delta \dagger$ \\
\hline Number of rats & 6 & 6 & \\
\hline \multicolumn{4}{|l|}{ Sucrase } \\
\hline Specific activity & $22.2 \pm 6.1$ & $7.60 \pm 3.4$ & -2.9 fold \\
\hline Total activity $\S$ & $3030 \pm 834$ & $1004 \pm 449$ & -3.1 fold \\
\hline \multicolumn{4}{|l|}{ ERKs } \\
\hline Specific activity & $0.377 \pm 0.004$ & $0.101 \pm 0.01$ & -3.7 fold \\
\hline Total activity\| & $5.15 \pm 0.07$ & $1.38 \pm 0.02$ & -3.7 fold \\
\hline
\end{tabular}

* Values are mean $\pm \mathrm{SD}$.

$\dagger$ Decrease of enzyme activity in PD 098059 group $v s$ control group.

$\$$ Specific activity of sucrase is expressed in units per gram mucosal protein.

$\S$ Total activity of sucrase is expressed as units per total intestinal mucosal mass.

T/ Specific activity of ERKs is expressed as units per milligram mucosal protein.

|| Total activity of ERKs is expressed as units per total intestinal mucosal mass.

shown by immunohistochemistry to be located in membranes of villus and crypt cells from which they transmit signals of extracellular origin to the nucleus (30). A recent study (28) on the detection of $\mathrm{p} 44 / \mathrm{p} 42$ ERKs by immunofluorescence on primary cultured human differentiated enterocytes has shown that p44/p42 ERKs were detected mainly in villus and crypt cell membranes with an increasing crypt to villi gradient of intensity (31). The same findings are shown in Figure $5 \mathrm{~A}$.

By contrast with ERKs, p38 MAP kinase was unresponsive to insulin since at different ages, there was no difference in the autoradiographic detection of the total and diphosphorylated forms of p38 MAP kinase between insulin-treated rats and control animals. The detection by autoradiography of diphosphorylated p38 MAP kinase revealed a progressive increase in phosphorylation with age although the total expression of p38 protein remained unchanged during growth. Immunohistochemistry showed that p38 MAP kinase was confined to the nuclei of enterocytes and was more abundant in the proximal duodenojejunum than in the distal ileum (not shown). In unstimulated cells, p38 MAP kinase associates with its substrate MAPKAP kinase (32). Stress stimuli induce phosphorylation of MAPKAP kinase-2 by p38 MAP kinase and the expulsion (nuclear export signal) of the complex from the nucleus (32).

Several studies conducted in vivo and in vitro $(1,5-7,33)$ have demonstrated that exogenous insulin is able to induce prematurely (before weaning) sucrase activity, sucrase protein, and sucrase mRNA levels. Likewise, in suckling and weaning rats, exogenous insulin stimulates the ontogenic expression of lactase and maltase with enzyme responses proportional to the dose of insulin given (6). These effects are mediated by the binding of the hormone to the extramembranous $\alpha$-subunits of the insulin receptor and by the autophosphorylation of the tyrosine kinase domain of the receptor $(4,7,12)$. In a preliminary study (12), we have shown that the postreceptor pathway transducing the signal downstream is not mediated by PI-3 kinase but likely by the cascade of Raf-Ras-GAP (GTPaseactivating protein) phosphorylations leading to the activation of ERKs. The detection of p44 and p42 ERKs in the rat small intestine and the stimulation of their activity by insulin prompted us to inhibit their activation, especially because these key enzymes down-regulate the mitogenic effects of insulin to the nucleus in a homodimerization form (ERK-ERK) where they activate transcription factors (30).

PD 098059 is a specific inhibitor of MKK that in turn activates p44 and p42 ERKs by phosphorylation of $\mathrm{Thr}^{183}$ and $\mathrm{Tyr}^{185}$. The administration to suckling pups and to weanling rats of low doses of PD 098059 clearly inhibited mucosal mass and the expression of BBM hydrolases. In addition, PD 098059 inhibited the premature stimulation of these enzymes by insulin compared with insulin-treated control animals. Administration in vivo of PD 098059 to weanling rats inhibited both sucrase and ERKs activities by three times. Our results obtained in vivo are in agreement with the in vitro data published by Aliaga et al. (31). These authors analyzed the effects of PD 098059, the inhibitor of MKK, on SI expression in primary cultures of human differentiated enterocytes, prepared with specimens of small intestines of fetuses ranging from 18 to $20 \mathrm{wk}$ of age and cultured during 5 to $7 \mathrm{~d}$. Treatment of these differentiated cells with 2 and $10 \mu \mathrm{M}$ PD 098059 significantly and dose dependently decreased the expression of SI by 22 and $55 \%$, respectively, with a significant reduction of both p42 and p44 ERK

Table 6. Response of rat immature small intestine to p38 MAP kinase inhibitor SB 203580 (d 12 to d 14 postpartum)*

\begin{tabular}{|c|c|c|c|c|c|c|}
\hline Variable & $\begin{array}{l}\text { Saline } \\
\text { controls }\end{array}$ & SB 203580 & $\begin{array}{c}P \\
\text { value† }\end{array}$ & Insulin & $\begin{array}{c}\text { SB } 203580+ \\
\text { Insulin }\end{array}$ & $\begin{array}{c}P \\
\text { valuet }\end{array}$ \\
\hline No. of rats & 8 & 8 & & 8 & 8 & \\
\hline \multicolumn{7}{|l|}{ Body wt (g) } \\
\hline Final (d 14) & $26.3 \pm 1.26$ & $27.1 \pm 1.70$ & NS & $24.1 \pm 1.55$ & $24.4 \pm 1.70$ & NS \\
\hline Intestinal length $(\mathrm{cm})$ & $44.5 \pm 2.31$ & $46.7 \pm 1.44$ & NS & $44.1 \pm 0.94$ & $45.4 \pm 1.32$ & NS \\
\hline Mucosal wt (mg/cm) & $9.59 \pm 0.51$ & $9.99 \pm 0.67$ & NS & $9.44 \pm 1.57$ & $9.35 \pm 1.58$ & NS \\
\hline Maltase total activity & $875 \pm 195$ & $893 \pm 285$ & NS & $1470 \pm 226$ & $2482 \pm 456$ & $<0.05$ \\
\hline $\mathrm{BBM}$ protein $(\mathrm{mg} / \mathrm{mL})$ & $3.92 \pm 1.55$ & $4.07 \pm 0.66$ & NS & $3.70 \pm 1.35$ & $3.77 \pm 0.95$ & NS \\
\hline
\end{tabular}

* Data are expressed as mean $\pm \mathrm{SD}$.

$\dagger$ Probability vs saline controls; NS, not significant.

$\ddagger$ Probability vs insulin controls.

$\S$ Total activity represents $\mathrm{mU}$ per total intestinal BBM.

II NA, no activity detected. 
activities. Treatment with $20 \mu \mathrm{M}$ PD 098059 was shown to significantly reduce the activity of lactase. Moreover, higher concentrations of PD 098059 were able to completely inhibit p42 ERK activity, SI expression, and lactase activity (31). Furthermore, insulin-induced differentiation of 3T3-L1 cells is blocked by ERK antisense oligonucleotides (34).

To analyze the potential role of p38 MAP kinase in the regulation of BBM enzymes, SB 203580, a specific inhibitor of p38 MAP kinase, was given at low doses in suckling rats. In rats treated with the inhibitor, mucosal mass and BBM hydrolases activities remained unchanged compared with saline-treated control animals. Surprisingly, in rats treated with SB 203580 and insulin, the inhibitor potentiated the effect of insulin by increasing both sucrase and maltase total activities but not lactase total activity. Also, SB 203580 had no effect on mucosal mass expressed by centimeter of gut length. Although several studies $(6$, $10,11,35,36)$ have documented that the regulation of the genes of SI and of maltase and their responsiveness to insulin differs from that of lactase, the effect of SB 203580 remains unexplained. It is possible that the inhibition of $\mathrm{p} 38$ MAP kinase determines an antiapoptotic effect upgrading cell differentiation and the responsiveness of sucrase and maltase to insulin.

Taken together, our results suggest that the ontogenic expression of BBM hydrolases and their premature stimulation by insulin are regulated, at least in part, by the activation of p44 and p42 ERKs but not by p38 MAP kinase. Further studies are warranted to clarify by which nuclear transcription factor(s) p44 and p42 ERKs initiate the transcription of SI, maltase, and lactase mRNA.

Acknowledgments. The authors thank Mark H. Rider for technical assistance and Dominique Vermeulen for preparation of the manuscript.

\section{REFERENCES}

1. Buts JP, De Keyser N, Kolanowski J, Van Hoof F 1990 Hormonal regulation of the rat small intestine: responsiveness of villus and crypt cells to insulin during the suckling period and unresponsiveness after weaning. Pediatr Res 27:161-164

2. Blazquez E, Lipshaw LA, Blazquez M, Foa PP 1975 The synthesis and release of insulin in fetal, nursing and adult rats: studies in vivo and in vitro. Pediatr Res 9:17-25

3. Buts JP, De Keyser N, Sokal EM, Marandi S 1997 Oral insulin is biologically active on rat immature enterocytes. J Pediatr Gastroenterol Nutr 25:230-232

4. Buts JP, De Keyser N, Marandi S, Maernoudt AS, Sokal EM, Rahier J, Hermans D 1997 Expression of insulin receptors and of a 60-kDa receptor substrate in rat mature and immature enterocytes. Am J Physiol 273:G217-G226

5. Buts JP, De Keyser N, Dive C 1988 Intestinal development in suckling rats: effect of insulin on the maturation of villus and crypt cell functions. Eur J Clin Invest 18:391-398

6. Buts JP, Duranton B, De Keyser N, Sokal EM, Maernoudt AS, Raul F, Marandi S 1998 Premature stimulation of rat sucrase-isomaltase (SI) by exogenous insulin and the analog $\mathrm{B}-\mathrm{ASP}^{10}$ is regulated by a receptor-mediated signal triggering SI gene transcription. Pediatr Res 43:585-591

7. Buts JP, De Keyser N, Romain N, Dandrifosse G, Sokal EM, Nsengiyumva TH 1994 Response of rat immature enterocytes to insulin: regulation by receptor binding and endoluminal polyamine uptake. Gastroenterology 106:58-68

8. Feng GS, Hui CC, Pawson T $1993 \mathrm{SH}_{2}$-containing phosphotyrosine phosphatase as a target of protein-tyrosine kinase. Science 259:1611-1614

9. Skolnik EY, Lee CH, Batzer AG, Vicentini LM, Zhov M, Daly RJ, Myers Jr MJ, Backer JM, Ulrich A, White MF, Schlessinger J 1993 The $\mathrm{SH}_{2} / \mathrm{SH}_{3}$ domain contain- ing protein Grb2 interacts with tyrosine-phosphorylated IRS-1 and Shc: implications for insulin control of Ras signalling. EMBO J 12:1929-1936

10. Traber PG, Wu GD, Wang W 1994 Novel DNA-binding proteins regulate intestine specific transcription of the sucrase-isomaltase gene. Mol Cell Biol 14:7340-7351

11. Hecht A, Torbey CF, Korsmo HA, Olsen WA 1997 Regulation of sucrase and lactase in developing rats: role of nuclear factors that bind to two gene regulatory elements. Gastroenterology 112:803-812

12. Marandi S, De Keyser N, Saliez A, Maernoudt AS, Sokal EM, Stilmant C, Rider MH, Buts JP 2001 Insulin signal transduction in rat small intestine: role of MAP kinases in expression of mucosal hydrolases. Am J Physiol 280:G229-G240

13. Marais R, Light Y, Paterson HF, Masson CS, Marshall CJ 1997 Differential regulation of Raf-1, A-Raf and B-Raf by oncogenic Ras and tyrosine kinases. J Biol Chem 272:4378-4383

14. Freed E, Symons M, McDonald SG, McCormick F, Ruggieri R 1994 Binding of 14-3-3 proteins to the protein kinase Raf and effects on its activation. Science 265:1713-1716

15. Lenormand P, Sardet C, Pagès G, L'Allemain G, Brunet A, Pouysségur J 1993 Growth factors induce nuclear translocation of MAP kinases (p42 mapk and p44 mrpk) but not of their activator MAP kinase kinase. J Cell Biol 122:1079-1088

16. Rothenberg PL, Lane WS, Karasik A, Backer J, White MF, Kahn CR 1991 Purification and partial sequence analysis of pp165, the major cellular substrate of the insulin receptor tyrosine kinase. J Biol Chem 266:8302-8311

17. Laemmli VK 1970 Changes in structural proteins during the assembly of the head of bacteriophage T4. Nature 277:660-685

18. Towbin H, Staechlin J, Gordon J 1979 Electrophoresis transfer of proteins from polyacrylamide gels to nitrocellulose sheets: procedure and some applications. Proc Natl Acad Sci USA 76:4350-4354

19. Lowry OH, Rosenbrough WJ, Farr AL, Randall RJ 1951 Protein measurement with the folin-phenol reagent. J Biol Chem 193:265-275

20. Schmitz JH, Preiser D, Maestracci BK, Ghosh JJ, Cerda JJ, Crane RK 1973 Purification of the human intestinal brush border membrane. Biochim Biophys Acta 323:98-112

21. Messer M, Dahlqvist 1966 A one step ultramicromethod for the assay of intestinal disaccharidases. Anal Biochem 14:376-392

22. Sempoux C, Guiot Y, Dubois D, Nollevaux MC, Saudubray JM, Nihoul-Fekete C, Rahier J 1998 Pancreatic B-cell proliferation in persistent hyperinsulinemic hypoglycemia of infancy: an immunohistochemical study of 18 cases. Mod Pathol 11:444-449

23. Lau KH, Farley J, Baylink D 1989 Phosphotyrosyl protein phosphatases. Biochem J 257:23-36

24. Kumps MP, Sefton BM 1988 Identification of multiple novel substrates of the v-Src, v-yes, v-fps, v-zos and v-erb-B oncogenic tyrosine protein kinases utilizing antisera against phosphotyrosine. Oncogene 2:305-315

25. Schaeffer HJ, Weber MJ 1999 Mitogen-activated protein kinases: specific messages from ubiquitous messengers. Mol Cell Biol 19:2435-2444

26. Han J, Lee JD, Bibbs L, Ulevitch RJ 1994 A MAP kinase targeted by endotoxin and hyperosmolarity in mammalian cells. Science 265:808-811

27. Han J, Jiang Y, Li Z, Kravchenko VV, Ulevitch RJ 1997 Activation of the transcription factor MEF2C by the MAP kinase p38 in inflammation. Nature 386:296-299

28. Schliess F, Haussinger D 2000 Cell hydration and insulin signalling. Cell Physiol Biochem 10:403-408

29. Buts JP, De Meyer R 1984 Intestinal development in the suckling rat: effects of weaning, diet composition and glucocorticoids on thymidine kinase activity and DNA synthesis. Pediatr Res 18:145-149

30. Khokhlatchev AV, Canagarajah B, Wilsbacher J, Robinson M, Atkinson M, Goldsmith E, Cobb MH 1998 Phosphorylation of the MAP kinase ERK-2 promotes its homodimerization and nuclear translocation. Cell 93:605-615

31. Aliaga JC, Deschenes C, Beaulieu JF, Calvo EL, Rivard N 1999 Requirement of the MAP kinase cascade for cell cycle progression and differentiation of human intestinal cells. Am J Physiol 277:G631-G641

32. Ben-Levy R, Hooper S, Wilson R, Paterson HF, Marshall CJ 1999 Nuclear export of the stress-activated protein kinase p38 mediated by its substrate MAPKAP kinase-2. Curr Biol 8:1049-1057

33. Arsenault P, Menard D 1994 Insulin influences the maturation and proliferation of suckling mouse intestinal mucosa in serum free organ culture. Biol Neonate 46:229-236

34. Sale EM, Atkinson PGP, Sale GL 1995 Requirement of MAP kinase for differentiation of fibroblasts to adipocytes, for insulin activation of p90 S6 kinase and for insulin or serum stimulation of DNA synthesis. EMBO J 14:674-684

35. Finn AL, Kuzhikandathil EV, Oxford GS, Itoh-Lindstrom Y 2001 Sucrase-isomaltase is an adenosine 3 ',5'-cyclic monophosphate-dependent epithelial chloride channel. Gastroenterology 120:117-125

36. Fang RX, Olds LC, Santiago NA, Sibley E 2001 GATA family transcription factors activates gene promoter in intestine CACO-2 cells. Am J Physiol 280:G58-G67 